ReVeLe - nº 2 - Jan/2011

\title{
A CONVERGÊNCIA POÉTICA DE MURILO MENDES
}

Milene Moraes - FALE/UFMG

Apesar da importância atribuída desde o início à poesia de Murilo Mendes, que estreou em livro em 1930 (Poemas), a recepção crítica de sua obra pode ser considerada tardia se a compararmos com os estudos críticos dedicados a poetas como Manuel Bandeira, Carlos Drummond de Andrade e João Cabral de Melo Neto. Essa ausência de abordagens não sucedeu de forma alguma por desmerecimento e pode ter ocorrido em virtude da posição desconcertante que Murilo sempre ocupou no panorama da literatura brasileira ou mesmo à própria ausência do poeta de seu país a partir de 1957 quando fixa-se definitivamente na Itália. No entanto, nos últimos anos esta carência de estudos está mudando, as abordagens vêm crescendo substantivamente e já constituem um “corpus” razoável.

A partir de um recorte específico deste corpus já substancial através do qual selecionamos as interpretações mais canônicas, ou seja, aquelas que já se sedimentaram na crítica literária brasileira, pudemos extrair alguns dados interessantes e traçar este breve mapeamento do estado atual da recepção crítica da poesia de Murilo Mendes. A partir deste trabalho instrumental extraímos certas divergências e convergências entre os críticos envolvidos, fato que nos possibilitou fixar o estabelecimento de duas correntes críticas.

A primeira corrente estabelece a divisão da obra poética de Murilo Mendes em duas fases e a atribuição de uma evolução qualitativa à segunda fase. Sumariamente esta divisão da obra em duas fases compreenderia uma fase surrealista mística/cristã, caracterizada, sobretudo, pela imagética de teor altamente onírico e/ou místico/cristão e uma fase mais voltada para a materialidade e a concisão da linguagem.

Entre os críticos que partilham esta perspectiva citada estão: Haroldo de Campos, Alfredo Bosi, João Alexandre Barbosa e Luiz Costa Lima. No interior desta 
ReVeLe - $\mathrm{n}^{\circ} 2$ - Jan/2011

corrente ocorre uma divergência ainda mais significativa que diz respeito ao livro indicador deste salto qualitativo, neste ponto, cada crítico elege um livro diferente para indicar o momento desta mudança, menos João Alexandre Barbosa que não realiza a eleição de nenhum livro em especial. Para Haroldo de Campos essa reviravolta está representada por Tempo Espanhol (1959), para Alfredo Bosi por Contemplação de Ouro Preto (1950) e para Luiz Costa Lima por Siciliana (1955). Há neste ponto algo que merece ser examinado com mais atenção e que, portanto, não será o tema desta nossa breve consideração, pois a análise dos pressupostos e argumentos que sustentam estas escolhas pode indicar possíveis impasses e contradições destas abordagens.

Por outro lado, há uma corrente crítica que se destaca por contestar diretamente a divisão qualitativa da obra muriliana em fases distintas, para estes críticos ela seria fundamentalmente, uma obra heterogênea e, portanto, torna-se até contraditório estabelecer uma divisão com o intuito de reduzi-la a alguma definição restritiva. Para eles, as "fases" murilianas estão completamente interligadas e não devem ser vistas como momentos isolados e excludentes no interior da trajetória do poeta. Dentre os críticos que partilham desta opinião encontram-se: Irene Miranda Franco, Joana Matos Frias, Júlio Castañon Guimarães, Laís Corrêa de Araújo, Murilo Marcondes de Moura e Sebastião Uchôa Leite.

A maioria destes críticos afirma a arbitrariedade e a inconsistência da divisão qualitativa da obra muriliana asseverando que esta atitude privilegiaria certo tipo de poética. Esta observação pode ser comprovada se observarmos a interpretação que Haroldo de Campos realiza da obra poética muriliana em "Murilo e o Mundo Substantivo" (1970). Como um dos idealizadores e porta-voz da Poesia Concreta, Haroldo privilegia e exalta na poesia muriliana a concretude da linguagem e o rigor construtivista na criação, justamente as características mais próximas das diretrizes do Concretismo. Assim sendo, não surpreende que o crítico eleja Tempo Espanhol como livro representativo da mudança de Murilo. Haroldo chega a elaborar um inventário vocabular dos termos deste livro que, semanticamente, estão ligados à ideia de concretude e rigor. Segundo Haroldo este fato atestaria uma "obsessão do 
ReVeLe - nº 2 - Jan/2011

concreto" na poesia de Murilo Mendes, mas, será que o próprio crítico também não sofreria desta mesma "obsessão"?

Percebe-se que os críticos da primeira corrente ao estabelecer a divisão em fases operam uma cisão na poesia muriliana entre uma poesia de expressão mais ligada à inspiração e intuição poéticas e uma poesia construtivista. Convém mencionar um fato observado com perspicácia por Murilo Marcondes de Moura (1995) de que esta tensão existe também no interior do próprio surrealismo e na própria atividade artística moderna

todas as discussões sobre a unidade de sua obra têm de contornar o difícil contraste, em sua trajetória, entre o predomínio de uma poética surrealista no início e o de uma poética construtivista (se ela de fato existiu) nos livros finais. $O$ que se pode observar é que tal tensão existe no interior do próprio surrealismo e também no de toda a arte moderna. (MOURA, 1995, p.30)

Ao nos referirmos à existência destas duas tendências convém mencionar que alguns críticos colocam-se implicitamente em posição distinta das correntes críticas nomeadas, como Davi Arrigucci, que mencionaremos posteriormente e o caso específico de José Guilherme Merquior que mantém-se afastado de qualquer referência a esta proclamada divisão concentrando-se na análise dos poemas de influxo surrealista.

Todo este trabalho de revisão da bibliografia crítica constitui um requisito básico de qualquer investigação científica que é a revisão de literatura específica sobre o assunto estudado, nossa pesquisa tem como um dos objetivos aprofundar este item comum, estudando os pressupostos e critérios empregados por estes críticos. Pois, acreditamos que a análise contrastiva das divergências entre tais correntes e a verificação da procedência da divisão qualitativa se justificam e são relevantes na medida em que podem esclarecer certos impasses presentes na recepção crítica da poesia de Murilo Mendes. Consideramos nosso trabalho como uma etapa inicial de reflexão que, espera-se, possa contribuir de alguma forma para uma melhor compreensão da complexa amplitude da obra de Murilo Mendes.

Particularmente a perspectiva apontada por Sebastião Uchôa Leite (2003) nos servirá de guia para a análise que pretendemos desenvolver. Segundo esta, a 
ReVeLe - $\mathrm{n}^{\circ} 2$ - Jan/2011

divisão qualitativa da poesia de Murilo Mendes ocultaria um aspecto decisivo de sua poética que se traduziria numa espécie de diálogo intertextual. Assim sendo, Uchôa Leite afirma que no último livro de poemas de Murilo lançado em vida Convergência (1970) "repercutem ecos da intensa aventura poética iniciada com Poemas em 1930." (2003, p.62).

Levando-se em conta o momento especial na trajetória muriliana representado por Convergência e assumindo como referencial crítico-teórico a perspectiva de Uchôa Leite (2003), acreditamos ser possível nestas nossas considerações, se não verificar, ao menos apontar como a leitura deste livro pode indicar a possibilidade de uma revisão desta bifurcação em fases e da separação drástica em termos de qualidade poética efetuada por parte da crítica, fatos inexistentes perante uma leitura mais atenta da obra muriliana em sua extensão. Para tanto e ainda tomando como fio condutor a perspectiva postulada por Uchôa, pretende-se empreender uma breve análise descritiva visando identificar dois vetores temático-formais recorrentes na poesia muriliana desde seus primeiros livros até o último.

Para Uchôa (2003), sempre houve uma permanente preocupação formal em Murilo, apesar de parecer, à primeira vista, devido à presença do tom surrealizante, que a poesia muriliana sempre se guiou pela desordem e pelo caos. A prova de que há uma preocupação formal em Murilo é que mesmo tendo assimilado características e procedimentos do surrealismo, não adotou o principal método do movimento: a escrita automática.

Pode-se afirmar que a heterogeneidade é uma das principais características da poesia muriliana, a própria absorção que Murilo realizou do surrealismo já deixa claro que esta, conjuntamente com o rigor construtivo, foram sempre fatores primordiais de sua poética. Esta heterogeneidade pode ser comprovada na medida em que Murilo realizou uma absorção "à brasileira” do surrealismo. Tal fato verificase já no seu primeiro livro, Poemas (1930), em que, conjuntamente com a atmosfera surrealizante, encontra-se a presença do modernismo brasileiro em certos procedimentos, temas e imagens, principalmente no que toca ao tom zombeteiro presente em boa parte do volume e que predominará no livro seguinte que é 
ReVeLe - nº 2 - Jan/2011

História do Brasil (1932). Neste volume, Murilo empreende através da paródia uma revisão crítica e irônica dos principais acontecimentos, símbolos e figuras de nossa História oficial. Vale recordar que este primeiro momento do modernismo é fortemente marcado por uma atitude de revolta e ruptura com o espírito beletrístico dominante da época, logo, a posição iconoclasta pelo viés do humor será a tônica das primeiras manifestações do movimento.

De fato, podemos considerar o humor como um dos vetores da poesia muriliana, na medida em que percebemos sua ocorrência em vários momentos ainda que sob outro tom que não o meramente sarcástico cujo representante maior é História do Brasil. Numa resenha sobre uma antologia de Murilo publicada na Inglaterra, Office humain, Antonio Candido observa que o humor ainda está presente na obra muriliana mesmo que de forma mais contida e sublimada se comparado com seus primeiros livros:

o humor, que o poeta preferiu abafar a partir de certa altura, [...] persiste todavia como elemento básico de perspectiva, e mesmo de composição, facilitando as combinações insólitas de tão grande efeito, e corrigindo certos pendores ocasionais para a grandiloqüência'.

Tal fato pode ser verificado em Convergência, mais precisamente em sua segunda parte denominada Sintaxe, na qual haverá uma recuperação plena do humor modernista através de processos altamente lúdicos de composição como o uso de paranomásias e de jogos de sonoridade. Para Uchôa (2003) "assim se retoma a antiga imagem do poeta-prestidigitador" cuja origem já estaria em Poemas, livro já então totalmente ‘construído’ e que contraria a lenda de ‘intuição poética' que sempre envolveu Murilo. Poemas como Dois Tempos, de Convergência, por exemplo, recordam muito os poemas-minutos e anedóticos oswaldianos e a ironia corrosiva dos próprios poemas de História do Brasil, mas, neste caso, é um personagem da história mundial que serve de motivo para o sarcasmo:

Ouviu-se um estampido: era Hitler cuspindo.

Ouviu-se um estampido: era Hitler cuspido.

\footnotetext{
${ }^{1}$ CANDIDO Apud MOURA, A Poesia como Totalidade, 1995, p.70.
} 
ReVeLe - nº 2 - Jan/2011

(Poesia Completa e Prosa, 1994, p.713) ${ }^{2}$

Como já mencionamos e nos referiremos ainda mais ao último livro de Murilo, convém falar um pouco de sua estrutura: Convergência divide-se em duas partes, sendo que a primeira engloba duas seções de poemas intituladas, respectivamente, "Grafitos" e "Murilogramas" e a segunda parte, conforme já aludimos, intitula-se “Sintaxe”. Na parte inicial, a primeira seção traz apontamentos sobre coisas, lugares e artistas e encontramos, na segunda seção, mensagens murilianas exclusivas a poetas e artistas. Segundo João Alexandre Barbosa (1974), estes dois segmentos de Convergência "serão modos de concretização, pela palavra, de uma 'convergência' fundamental", ou seja, nestes poemas o poeta Murilo Mendes (re) lê e homenageia toda uma tradição cultural e artística a qual ele próprio se filia.

Vale a pena citar mais um poema de "Sintaxe", "A Pedra Pomes", em que o humor surge devido à própria ludicidade do procedimento de construção por meio de jogos de palavras, aliterações e assonâncias, o que resulta em um poema à maneira dos populares trava-línguas

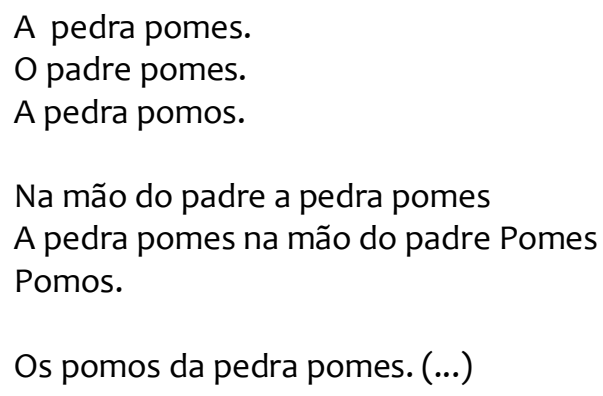

A consideração da heterogeneidade poética é um fato importante já que este elemento pode ser verificado como uma das principais características da modernidade poética conforme indicam críticos como Alfonso Berardinelli e Octavio Paz. Segundo Berardinelli (2007) a poesia moderna joga com o heterogêneo e o desafia, sendo capaz mesmo de eliminar o sujeito monologante e o distribuir numa pluralidade de vozes. Já Octavio Paz (1984) ressalta que o moderno não pode ser caracterizado somente por sua novidade, já que nem todo novo é moderno, mas, 
ReVeLe - nº 2 - Jan/2011

principalmente, por sua heterogeneidade e multiplicidade. De fato, até mesmo o próprio modernismo brasileiro é tido como um movimento híbrido, um verdadeiro complexo estilístico cujo denominador comum foi uma permanente atitude de renovação e (MERQUIOR, 1994; NUNES, 1975) que abrigou poéticas tão diversas e singulares como a do próprio Murilo Mendes.

Outro fator que atesta a heterogeneidade muriliana é que o poeta realizou um intercâmbio peculiar entre Surrealismo e Catolicismo, neste ponto, é José Guilherme Merquior (1994) quem nos esclarece como foi possível esta junção. Segundo o crítico, o projeto do Surrealismo não era em substância estético, mas, antes de tudo, de caráter existencial, por isso: "seu espírito se deixa entender melhor quando cotejado com as manifestações simbólicas das grandes religiões, não com estilos artísticos" (1994, p.12).

Merquior menciona ainda outro fator importante que também elucida esta questão, trata-se da forma ambivalente com que Murilo assimilou a doutrina cristã: por meio da rebeldia e da insolência. O poeta não se rendeu ao dogmatismo moralizante do cristianismo concebendo-o como uma via para a reflexão sobre o estar-no-mundo. Assim sendo, o crítico afirma que o cristianismo de Murilo, além de agônico, é também sacrílego, pois o poeta irá questionar, insolentemente, alguns dos principais dogmas religiosos. Estas insolências religiosas praticadas por Murilo provavelmente se nutriam, em parte, como ressalta Merquior, do próprio iconoclasmo surrealista. Mas enquanto que a maior audácia de um Max Ernst consistia em pintar a Virgem aplicando palmadas ao Menino Jesus ${ }^{2}$, a ousadia de Murilo ia mais longe, chegando mesmo a desafiar o próprio Criador em "Poeta Nocaute"

\footnotetext{
Intimaremos Deus

A não repetir a piada da Criação

Salvaremos os que deviam nascer depois

E se Deus ficar firme

Anunciaremos à Virgem Maria

Que nunca mais deverá nascer ninguém.
}

\footnotetext{
${ }^{2}$ Merquior se refere ao quadro de Ernst intitulado “A Virgem espanca o Menino Jesus vigiada por três testemunhas: André Breton, Paul Éluard e o Próprio Pintor”, 1926.
} 
ReVeLe - nº 2 - Jan/2011

$(P C P$, p.242)

Ainda no que concerne à atmosfera surrealizante e à dimensão religiosa/metafísica da poesia de Murilo, destaca-se um apontamento extremamente relevante feito por Moura (1995) para quem Murilo, com suas abstrações desconcertantes, foi o responsável pela abertura de uma vertente singular e negligenciada na poesia brasileira contemporânea a qual o poeta não renunciaria

\footnotetext{
as suas inquietações metafísicas, estreitamente aliadas a uma generosidade incomum para com o mundo sensível, não têm antecedentes entre nós, e para exprimi-las o poeta teve que inventar uma linguagem própria. Algo tão difícil de ser conquistado não poderia ter sido simplesmente abandonado, e o poeta, nos livros seguintes, apenas redimensionou-a (MOURA, 1995, p.193)
}

Podemos citar como mais um dos vetores temático-formais da poesia muriliana a presença da mulher quase sempre envolvida numa atmosfera eróticomística causando uma nítida tensão entre o sagrado e o profano. Segundo Bosi (2004) a palavra do poeta sacraliza todos os fenômenos, por isso, "a presença do eterno-feminino (a Mulher, Berenice, Eva) ora opõe-se ora une-se às aspirações religiosas" (2004, p.450).

Para Costa Lima (2002), o corpo feminino é “o ícone do tempo", por isso a mulher representaria, carnalmente, a passagem atroz do tempo e este seria o tema principal de O Visionário (1941). Basta atentarmos para os títulos dos poemas deste livro para verificar a procedência da observação de Luiz Costa Lima. Em vários deles a mulher aparece representada em várias fases e papéis sociais: "Mulher em todos os tempos", "A mãe do primeiro filho", "Mulher em três tempos", "Menina em quatro idades", “Duas irmãs", "Uma órfã adota a humanidade”, “A namorada de Lázaro", "A noiva” "A filha do caos" dentre outros.

Também é possível encontrar a presença do feminino em Convergência num poema como o Grafito para Ipólita. Porém, como ressalta Costa Lima (2002), a passagem do tempo agora é acompanhada no percurso da própria memória e não mais pelas deformações do corpo feminino 
ReVeLe - nº 2 - Jan/2011

Ipólita, a putain do fim da infância,

Nascera em Juiz de Fora, a família em Ferrara,

Seus passos feminantes fundam o timbre.

Marcha, parece, ao som do gramofone.

A cabeleira-púbis, perturbante.

Os dedos prolongados em estiletes.

Os lábios escandindo a marselheza

Do sexo. Os dentes mordem a matéria.

Por ela meus sentidos progrediram.

Por ela fui voyeur antes do tempo.

$$
\text { (PCP, p.631/632) }
$$

Ao atribuir a Ipólita a responsabilidade de sua precocidade de voyeur o poeta chama a atenção para mais um dos motivos recorrentes de sua poética que é a questão do olhar. Neste ponto, partimos do último livro de Murilo para o primeiro, que possui como título do segundo capítulo justamente o vocábulo "ângulos" que contém certa referência à visualidade. Esta alusão pode ser percebida também no título de alguns poemas disseminados pelo volume em que o poeta recorre a certa terminologia pictórica como, por exemplo, "Perspectiva da sala de jantar" em que a mulher é representada sensualmente em toda a sua voluptuosidade, sendo o espaço que ela habita comparado a uma "natureza morta"

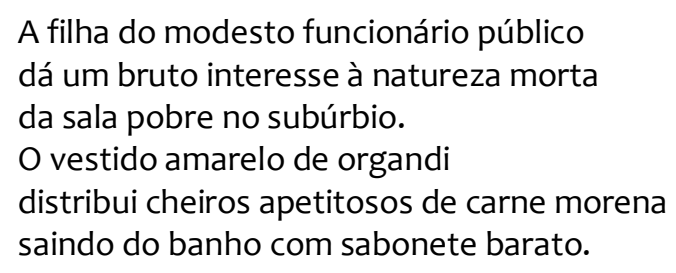

(PCP, p. 92)

Essa relação de Murilo com a visualidade já foi verificada de forma muito perspicaz por Júlio Castañon Guimarães (1993), que afirma que a visualidade na obra muriliana aponta para duas vertentes: de um lado, os elementos puramente visuais que são suscitados de formas diversas, devido à alta plasticidade das suas 
ReVeLe - nº 2 - Jan/2011

imagens e, por outro lado, a própria presença das artes plásticas, seja na referência a esta arte ou artistas específicos.

Os títulos de outros livros também denotam a presença marcante da visualidade em Murilo, como é o caso de Contemplação de Ouro Preto (1954) e do já citado O Visionário. Neste último, em especial, Castañon (1993) sublinha que a visão seria a base da elaboração poética e implicaria num recurso ao objeto de visão no seu sentido físico, daí a grande recorrência do verbo ver ao longo de todo o livro. Em “Formas Alternadas”, por exemplo, ele aparece repetidamente

\author{
Vi a menina crescendo \\ Na sombra de sua mãe. \\ Vi a mãe dela sumindo, \\ O corpo da outra aumentando \\ Vi a posição dos corpos \\ Mudando sempre no espaço \\ (...) \\ $(P C P, p .200)$
}

Podem ser observadas outras relações com a visualidade, não apenas no nível verbal. É o caso da recorrência, como aponta Castañon (1993), da presença de certos sinais gráficos em vários poemas de livros como Tempo Espanhol e também em Convergência. Dentre outros sinais podemos ressaltar: o caso do \& que substitui a conjunção "e"; do círculo em negrito $(\bullet)$ que separa as estrofes ou conjuntos de versos de certos poemas; o caso da barra (/) que ocorre no interior de certos versos e também nos textos de prosa; o sinal de igual (=), o hífen (-); o sinal de adição (+) etc. Outro agente gráfico importante em certos poemas, principalmente nos de Convergência, é a utilização do espaço da página em que o poema se inscreve. Vale recordar que a consideração das propriedades espaciais do poema tem como texto inaugural o Un Coup de Dés de Mallarmé, poeta que, não por acaso, é citado inúmeras vezes por Murilo tanto em Convergência quanto em outras obras.

Vale conferir um poema de Convergência que Castañon cita a este respeito. Trata-se do "Grafito num muro de Roma" em que o espaço no interior dos versos representa visualmente o roer de que fala o próprio poema 
Um verme enorme rói Um verme inerme rói Qualquer julgamento
Presente futuro

Pessoal universal

Miguelangelesco ou não.

$(P C P, p .627)$

Para Joana Matos Frias (1999), Convergência ocupa uma posição bem particular na trajetória de Murilo, surge ao mesmo tempo como o ponto-limite de um experimentalismo com a linguagem e como um ponto de chegada de uma obra em incansável metamorfose. Neste ponto convém mencionar uma questão importante e muito polêmica na recepção crítica de Murilo Mendes, particularmente no que concerne a Convergência: a sua ligação com a poesia concreta.

O Concretismo propunha que o poema devia ser trabalhado em todas as suas potencialidades verbais, sonoras e visuais e, para a realização de tal intento, os poetas concretistas utilizaram as mais variadas técnicas e procedimentos, conferindo elevado destaque a sonoridade, a valorização do espaço como elemento estruturador, a disposição das palavras na página e a abolição da sintaxe.

De fato, a relação de Murilo e, mais precisamente, de Convergência com o Concretismo é explícita pelo próprio fato de o poeta ter publicado, anteriormente ao lançamento de Convergência, uma série de poemas desta obra na revista dos poetas concretos Invenção ( $n^{\circ} 5$, nov. 66 - jan. 67).

Porém, nós não julgamos que Murilo tenha aderido ao Concretismo como busca de uma aceitação tardia nos meios literários o que contraria, neste caso, o posicionamento do crítico Davi Arrigucci (1997) que desqualifica completamente Convergência e boa parte da produção muriliana delimitada pela primeira corrente como a "segunda fase", por "sua denotatividade explícita e pura preocupação formal" chegando a acusar o poeta de puro "modismo momentâneo".

Um fato importante que pode elucidar esta questão é que a Poesia Concreta obteve aceitação de outros poetas modernistas também consagrados, como João Cabral de Melo Neto e Manuel Bandeira. Estes demonstraram simpatia com o 
ReVeLe - nº 2 - Jan/2011

movimento concretista tanto em declarações, como em seus próprios textos, através da assimilação de todo um repertório de certos procedimentos e técnicas tidas como concretistas e, que por sua vez, os próprios concretos tomaram de empréstimos a diversos escritores e poetas modernos que constituíram o “paideuma concretista”, como: Mallarmé, Eliot, Pound, Joyce, cummings etc. Esta aproximação de outros poetas com o Concretismo, por meio da incorporação de certos procedimentos e técnicas valorizadas e apropriadas pelos concretos, parece tornar improvável a busca de uma aceitação tardia nos meios literários por parte de Murilo, pois, não se trata sequer de um caso individualizado.

É ainda Joana Matos Frias (1999) quem recorda, com muita perspicácia e rigor, que os procedimentos empregados por Murilo em Convergência que apontariam para certa influência concretista também foram explorados por vários autores franceses de procedência surrealista e mesmo alguns que se afastaram do Surrealismo posteriormente como: Robert Desnos, Benjamin Péret, Jacques Prévert, Henri Michaux, Raymond Queneau. Como Murilo tinha amplo conhecimento das obras de autores franceses, notadamente dos surrealistas, também não se pode ignorar e anular a importância que estes autores possam ter tido para o poeta no que tange a exploração das potencialidades lúdicas das palavras, principalmente nesta sua última obra poética.

Pudemos observar nestas nossas breves considerações algumas linhas de força bem como certos temas e procedimentos que perpassam a obra de Murilo desde seu início até o seu último livro e que demonstram uma total unidade e convergência em sua produção poética. Desta forma é muito significativo -e indica uma escolha nada casual- o fato de seu último livro possuir como título justamente o vocábulo convergência, que possui como carga semântica a idéia de ponto em que objetos ou propriedades se encontram. Podem ser identificadas neste livro, ainda que com certos redimensionamentos e metamorfoses, as direções e características predominantes e orientadoras desta obra poética singular.

Perscrutando atentamente a obra poética de Murilo Mendes é possível perceber, além de sua “comovente lição de coerência” (BARBOSA, 1974), uma total autonomia do poeta em relação a quaisquer propostas programáticas, pois, como 
ReVeLe - nº 2 - Jan/2011

afirma Laís Corrêa de Araújo (2000), Murilo sempre se mostrou insatisfeito com toda forma de acomodação e institucionalização da poesia.

Portanto, uma leitura da obra poética muriliana que se pretenda mais aprofundada e reflexiva deve encará-la como uma obra em contínua transformação/metamorfose, uma obra proteiforme (FRIAS, 2002), que se refaz constantemente sob um fundo permanente e imutável. Murilo evidencia, através da convergência de sua produção poética, a importância e a excepcionalidade de sua obra, que desde sua gênese foi sempre pautada pela liberdade de criação conquistada pelos poetas modernos. Confirma assim o que ele próprio escreveu em "Novíssimo Orfeu" e que pode ser tomado como um princípio norteador de toda a sua obra

Vou onde a poesia me chama

(PCP, p.361)

\section{REFERÊNCIAS:}

ARAÚJO, Laís Corrêa de. Murilo Mendes - Ensaio Crítico, Antologia e Correspondência. São Paulo: Perspectiva, 2000.

ARRIGUCCI JÚNIOR, Davi. O Cacto e as Ruínas. A Poesia entre Outras Artes, São Paulo: Ed. Duas Cidades, 1997.

BARBOSA, João Alexandre. Convergência poética de Murilo Mendes. A metáfora crítica. São Paulo: Ed. Perspectiva, 1974, p.117-136.

BERARDINELLI, Alfonso. Da poesia à prosa. São Paulo: Cosac Naify, 2007.

BOSI, Alfredo. História Concisa da Literatura Brasileira. $43^{\text {a }}$ ed. São Paulo: Cultrix, 2004 .

CAMPOS, Haroldo de. Murilo e o Mundo Substantivo. Metalinguagem e Outras Metas. São Paulo: Perspectiva, 1970, p.39-45. 
ReVeLe - nº 2 - Jan/2011

FRANCO, Irene Miranda. Murilo Mendes: pânico e flor. Rio de Janeiro: Sette Letras; Juiz de Fora: Centro de Estudos Murilo Mendes - UFJF, 2002.

FRIAS, Joana Matos. O Erro de Hamlet: poesia e dialética em Murilo Mendes. Rio de Janeiro: Sette Letras; Juiz de Fora: Centro de Estudos Murilo Mendes - UFJF, 2002.

FRIAS, Joana Matos. Murilo Mendes e o cosmotexto ideogramático. Línguas e Literaturas, Porto, nº XVI, 1999, p.125-142.

GUIMARÃES, Júlio Castañon. Territórios/Conjunções. Poesia e Prosa Crítica de Murilo Mendes, Rio de Janeiro: Imago, 1993.

LEITE, Sebastião Uchôa. A meta múltipla de Murilo Mendes. Crítica de ouvido. São Paulo: Cosac Naify, 2003, p.61-72.

LIMA, Luiz Costa. Tríptico sobre Murilo Mendes. Intervenções. São Paulo: Edusp, 2002, p.71-110.

MENDES, Murilo. Poesia Completa e Prosa. Rio de Janeiro: Nova Aguilar, 1994.

MERQUIOR, José Guilherme. Notas para uma Muriloscopia. In: MENDES, Murilo. Poesia Completa e Prosa. Rio de Janeiro: Nova Aguilar, 1994, p.11-21.

MOURA, Murilo Marcondes de. A Poesia como Totalidade. São Paulo: Edusp, 1995.

NUNES, Benedito. Estética e correntes do Modernismo. Affonso Ávilla (Org.). 0 Modernismo. São Paulo: Perspectiva, 1975, 39-53.

PAZ, Octavio. Os Filhos do Barro. Rio de Janeiro: Nova Fronteira, 1984. 